\title{
RANCANG BANGUN ALAT UJI EMISI EKONOMIS MENGGUNAKAN SENSOR GAS MQ2 DAN MQ9 BERBASIS ARDUINO
}

\author{
Mohamad Adzina Mukhlasin \\ Teknik Mesin, Teknik, Universitas Hasym asy’ari, Email : adzina.koboy@gmail.com
}

Nur Kholis

Teknik Elektro, FakultasTeknik, Universitas Hasym asy’ari, Email: nurkholis.unhasy@yahoo.com

\section{Retno Eka Pramitasari}

Teknik Mesin, Fakultas Teknik, Universitas Hasym asy’ari, Email: retnomita91@ gmail.com

Emisi gas buang yang dihasilkan kendaraan bermotor semakin meningkat seiring dengan bertambahnya jumlah kendaraan bermotor yang ada. Carbon monoxide $(\mathrm{CO})$ dan Hydro Carbon (HC) adalah zat berbahaya yang terkandung dalam emisi gas buang. Penelitian ini bertujuan membuat alat uji emisi (prototype) untuk mengukur kadar $C O$ dan $H C$ pada emisi gas buang. Jenis penelitian ini merupakan penelitian eksperimen dengan metode rancang bangun waterfall model. Alat uji emisi (prototype) berbasis arduino dengan sistem kerja konsentrasi $C O$ dan $H C$ pada emisi akan dibaca oleh sensor $M Q 2$ dan $M Q 9$ yang terhubung dengan arduino dan ditampilkan pada layar LCD berupa angka digital dengan menggunakan program Bahasa C. Selanjutnya pada prototype diambil data dan diperbandingkan dengan data pada gas analyzer menggunakan metode Uji T. Hasil pengujian kadar $C O$ dan $H C$ pada alat uji emisi (prototype) dengan hasil pengujian gas analyzer masih menunjukkan perbedaan yang signifikan dengan nilai signifikasi pembacaan kadar $C O$ sebesar 0.319 dan kadar HC sebesar 0.896 .

Kata Kunci: Emisi gas buang, $M Q 2, M Q 9$, Arduino

\section{PENDAHULUAN}

Seiring dengan perkembangan zaman, jumlah kendaraan yang ada semakin meningkat dan hal ini menyebabkan tingkat polusi yang ditimbulkan emisi gas buang semakin tinggi. Maka dari itu perlu dilakukan upaya untuk menekan angka polusi yang disebabkan oleh kendaraan bermotor.

Di Indonesia salah satu upaya yang dilakukan oleh pemerintah untuk menekan angka polusi adalah dengan adanya Peraturan Menteri Negara Lingkungan Hidup Nomor 05 Tahun 2006 tentang ambang batas emisi gas buang kendaraan bermotor. Aturan tersebut menjelaskan bahwa kendaraan bermotor wajib melakukan uji emisi gas buang dengan metode yang telah ditentukan dan hasil pengujian kadar emisi gas buang kendaraan bermotor tersebut tidak boleh melewati nilai ambang batas yang telah ditetapkan.

Standar nilai ambang batas emisi gas buang yang 
ditetapkan oleh Menteri Negara Lingkungan Hidup dengan parameter kadar konsentrasi CO (Carbon Monoxide) dalam satuan persen (\%) dan HC (Hydro Carbon) dalam satuan ppm (part per milion) adalah 4.5\% dan 12000 ppm untuk sepeda motor 2 langkah dengan tahun $<2010$, 5.5\% dan 2400 ppm untuk sepeda motor 4 langkah dengan tahun $<2010,4.5 \%$ dan 2000 ppm untuk sepeda motor 2 dan 4 langkah dengan tahun $\geq 2010$. Nilai tersebut merupakan standart emisi gas buang untuk kendaraan bermotor kategori L dengan metode uji pada keadaan idle. Peraturan tersebut berlaku untuk semua jenis kendaraan bermotor kategori L yang telah diproduksi, dirakit, diimpor dan beroperasi di wilayah Republik Indonesia (Peraturan Menteri Negara Lingkungan Hidup No. 05 Tahun 2006).

Uji emisi bertujuan untuk mengukur tingkat polusi yang disebabkan oleh proses pembakaran mesin. Namun tidak semua pemilik kendaraan bermotor mempunyai kesadaran untuk merawat dan melakukan pengujian emisi gas buang yang dihasilkan kendaraan tersebut secara rutin di bengkel resmi. Hal ini dikarenakan adanya beberapa faktor yang menjadi kendala dalam melakukan servis kendaraan di bengkel resmi diantaranya, biaya servis, biaya penggantian part yang mahal, banyaknya proses administrasi di bengkel (Hidayat, 2015). Untuk mengetahui perbedaan biaya servis yang ditetapkan oleh bengkel resmi dan tidak resmi dapat diketahui dari hasil survei yang dilakukan oleh penulis dalam pra-eksperimen.

Biaya servis di bengkel resmi lebih mahal dari bengkel biasa (tidak resmi) dengan selisih antara Rp 10.000 - Rp 20.000. dan biaya servis juga dapat bertambah apabila ada penggantian spare part lainya yang mengalami aus atau trouble. Namun untuk pengujian emisi gas buang kendaraan bermotor hanya dapat dilakukan di bengkel resmi yang mempunyai Gas analyzer dikarenakan pada bengkel tidak resmi tidak memiliki alat uji emisi gas buang kendaraan bermotor, hal ini terjadi karena harga alat uji emisi gas buang kendaraan bermotor sangat mahal dengan harga mencapai sekitar 45 juta (Hidayat, 2015).

Rancangan alat uji ini menggunakan 2 sensor gas, yaitu sensor gas $M Q 2$ yang digunakan untuk mendeteksi kadar $H C$ pada emisi gas buang dan sensor gas $M Q^{9}$ yang digunakan untuk mendeteksi kadar $C O$. Dalam hal ini alat uji emisi yang dirancang berbasis Arduino yang mempunyai desain dan perangkat yang lebih kompleks dan mudah untuk digunakan dan hasil pengujian yang akan ditampilkan pada layar LCD berupa angka digital.

\section{METODE}

Penelitian ini menggunakan metode rancang bangun. Rancang bangun adalah kegiatan menerjemahkan hasil analisa kedalam sebuah perangkat atau sistem menjadi suatu kesatuan yang utuh dan berfungsi atau memperbaiki sistem yang suda ada. Rancang bangun dalam penelitian ini menggunakan rancangan Waterfall Model. Waterfall Model adalah pengerjaan suatu sistem yang dilakukan secara berurutan atau linier. Rancangan ini memiliki 4 langkah yaitu: Analisa, Design, Code, dan Test (Pressman, 2010). Tetapi untuk mengetahui kesempurnaan alat maka dilaksanakan uji eksperimental yaitu uji $\mathrm{T}$ untuk mengetahui nilai signifikasi pembacaan kadar $C O$ dan $H C$ pada alat uji penelitian (prototype) terhadap alat uji standar.

Desain penelitian ini dilakukan berdasarkan diagram alir (Flowchart) sebagai berikut.

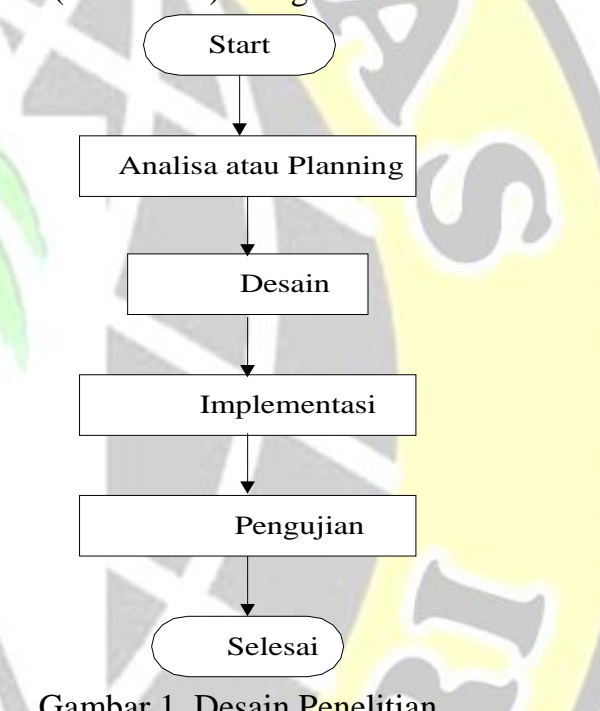

Gambar 1. Desain Penelitian

Setelah didapatkan data dan ditentukan spesifikasi dari setiap komponen yang dibutuhkan dalam rancang bangun alat uji emisi, maka langkah pertama adalah pembuatan hardware.

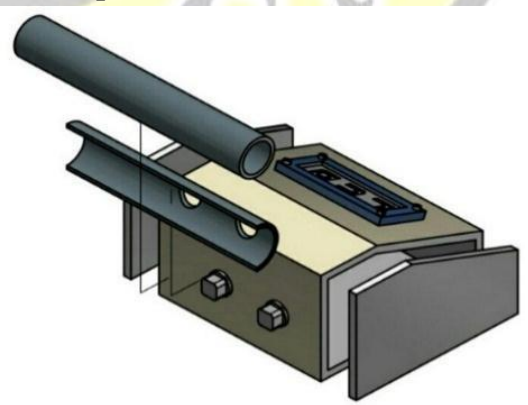

Gambar 2. Desain Alat Uji Emisi (Prototype) Tampak Belakang

Adapun komponen yang digunakan dalam alat uji penelitan meliputi: Arduino, LCD, sensor gas MQ2 dan MQ9, adaptor, pipa dan kabel. Setelah hardware selesai maka langkah selanjutnya 


\section{Rancang Bangun Alat Uji Emisi Ekonomis Berbasis Arduino}

adalah pembuatan Software.

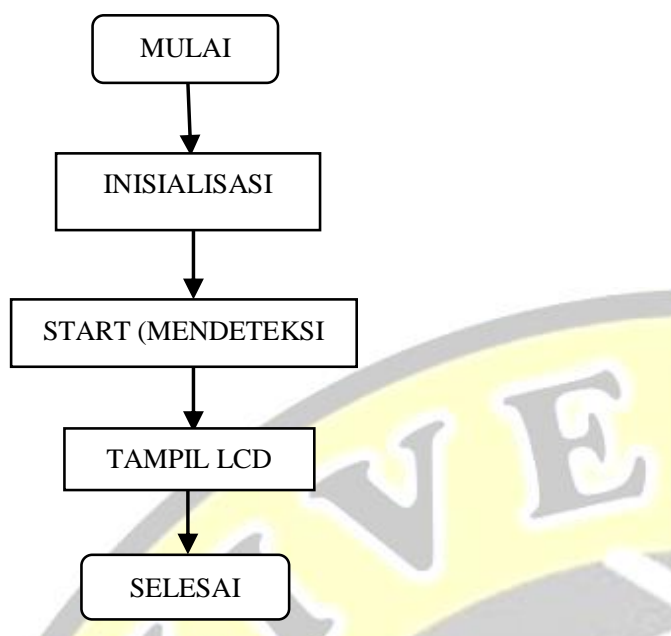

Gambar 3. Alur Kerja Sistem Alat Uji (Prototype)

Setelah proses pembuatan Hardware dan software selesai maka dapat di integrasikan. Langkah pertama yang harus dilakukan dalam integrasi adalah menghubungkan hardware dengan PC menggunakan kabel USB, kemudian buka program arduino pada PC, click "tools" kemudian clik "port", jika port aktif maka arduino dapat dijalankan dan langkah selanjutnya buka program yang sudah dibuat untuk alat uji emisi gas buang kemudian upload program tersebut ke dalam arduino.

Pada penelitian ini, pengambilan data menggunakan data kuantitatif yang diperoleh dari pembacaan hasil pengujian alat uji resmi dan alat uji penelitian (prototype) berupa angka/nilai digital pada layar LCD alat uji emisi, yang akan di analisis secara deskriptif berupa penunjukan diagram hasil pengujian.

Pengujian dilakukan pada sepeda motor Jupiter MX King 150 cc 2016 untuk mengetahui kadar $H C$ dan $C O$ yang ada pada emisi gas buang sepeda motor tersebut. Pengambilan data dilakukan sebanyak 3 kali dari setiap RPM pada variasi pengujian, kemudian diambil rata-rata untuk mendapatkan data hasil pengujian. Analisis data yang dilakukan adalah analisa deskriptif yang didapatkan dari hasil pengujian yang dilakukan pada emisi gas buang sepeda motor. Pengujian alat ini dilakukan pada putaran 1300 RPM, 1500 RPM, 2000 RPM, 2500 RPM dan 3000 RPM.

\section{HASIL DAN PEMBAHASAN}

Alat uji emisi (Prototype) dibuat sesuai dengan desain yang direncanakan. Alat uji emisi tersebut memiliki layar LCD 16 x 2 yang berfungsi sebagai monitor yang menunjukkan hasil pengujian kadar $C O$ dan $H C$ pada kendaraan bermotor disertai dengan tombol reset untuk memulai pengujian yang baru. Alat ini menggunakan sumber listrik dengan arus 12 volt dari adapter yang terhubung dengan pin $\mathrm{V}$-in yang ada pada Arduino. Terdapat 2 sensor yang berfungsi sebagai pendeteksi kadar $\mathrm{CO}$ dan $\mathrm{HC}$ pada emisi kendaraan bermotor. Terdapat juga 2 pipa PVC yang berfungsi sebagai pencekam dan ruang untuk emisi yang diuji sehingga pada saat pengujian emisi tidak bercampur dengan udara bebas

Hasil pembacaan kadar CO (Carbon Monoxide) pada emisi sepeda motor Jupiter MX King 150 cc 2016.

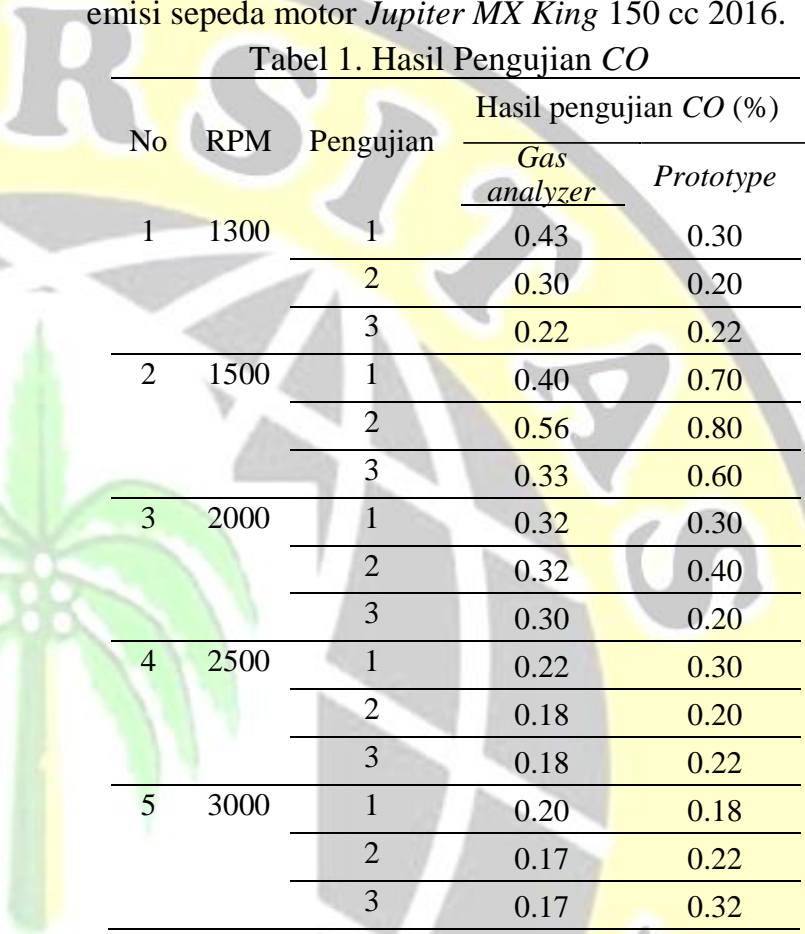

Dari data pada tabel di atas maka didapatkan rata-rata hasil pengujian menggunakan gas analyzer dan prototype sebagai berikut.

Tabel 2. Rata-rata Hasil Pengujian $C O$

\begin{tabular}{cccc}
\hline No. & RPM & $\begin{array}{c}\text { Hasil Pengujian } \begin{array}{c}\text { Gas }(\%) \\
\text { analyzer }\end{array} \\
\text { Prototype }\end{array}$ & $\begin{array}{c}\text { Pry } \\
1\end{array}$ \\
\cline { 2 - 4 } & 1300 & 0.31 & 0.24 \\
\hline 2 & 1500 & 0.43 & 0.70 \\
\hline 3 & 2000 & 0.31 & 0.30 \\
\hline 4 & 2500 & 0.19 & 0.24 \\
\hline 5 & 3000 & 0.18 & 0.24 \\
\hline Dari & tabel di & atas dapat & diketahui hasil
\end{tabular}
pembacaan dari alat uji resmi (gas analyzer) dan alat uji penelitian (prototype), terdapat perbedaan pembacaan dari kedua alat uji. Pembacaan alat uji emisi (prototype) pada putaran 1300 RPM menunjukkan hasil pembacaan $C O$ sebesar $0.24 \%$, pada putaran 1500 RPM menunjukkan hasil pembacaan $C O$ sebesar $0.70 \%$, pada putaran 2000 RPM menunjukkan hasil pembacaan $C O$ sebesar 
$0.30 \%$, pada putaran 2500 RPM menunjukkan hasil pembacaan $C O$ sebesar $0.24 \%$, pada putaran 3000 RPM menunjukkan hasil pembacaan $C O$ sebesar $0.24 \%$.

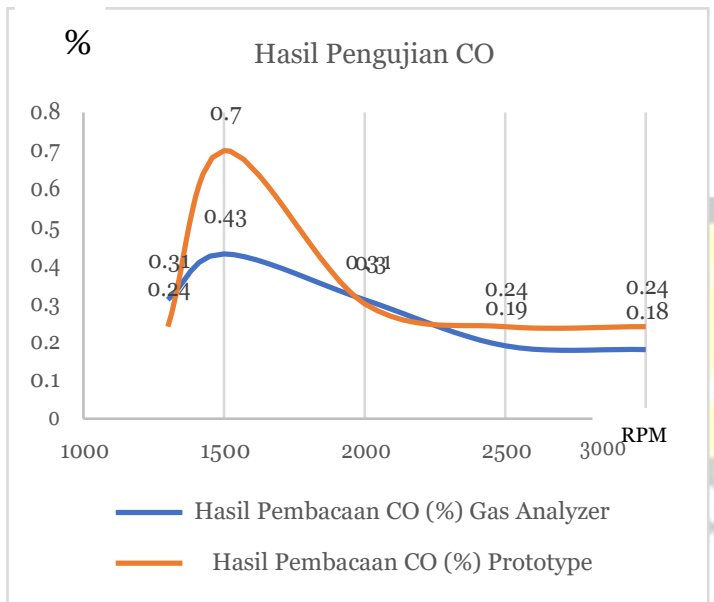

Gambar 9. Grafik Hasil Pengujian CO (\%)

Hasil pembacaan kadar HC (Hydro Carbon) pada emisi sepeda motor Jupiter MX King 150 cc 2016.

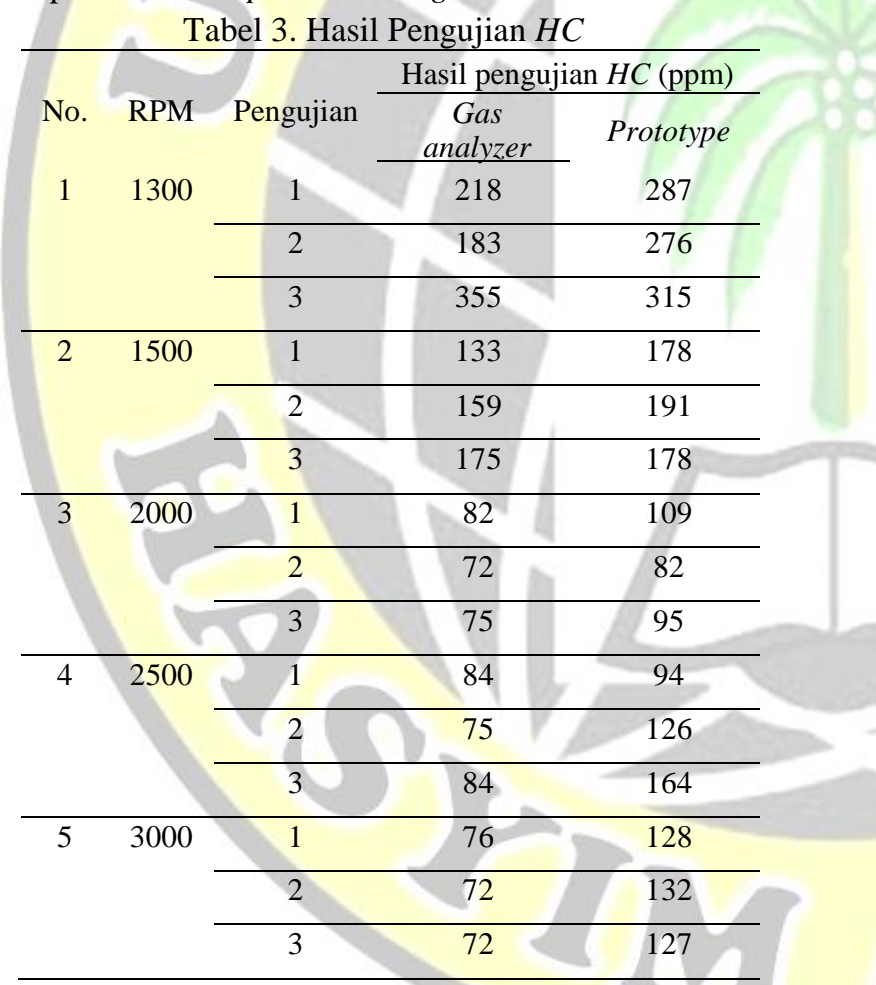

Dari data pada tabel di atas maka didapatkan ratarata hasil pengujian menggunakan gas analyzer dan prototype sebagai berikut

Tabel 4. Rata-rata Hasil Pengujian $H C$

\begin{tabular}{cccc}
\hline \multirow{2}{*}{ No. } & \multirow{2}{*}{ Rpm } & \multicolumn{2}{c}{ Hasil Pengujian $H C(\mathrm{ppm})$} \\
\cline { 3 - 4 } & & analyzer & Prototype \\
\hline 1 & 1300 & 252 & 292 \\
\hline 2 & 1500 & 155 & 182 \\
\hline 3 & 2000 & 76 & 95 \\
\hline 4 & 2500 & 81 & 128 \\
\hline
\end{tabular}

\begin{tabular}{llll}
\hline 5 & 3000 & 73 & 129 \\
\hline
\end{tabular}

Dari tabel di atas dapat diketahui hasil pengujian kadar HC menggunakan alat uji resmi (gas analyzer) dan alat uji penelitian (prototype), terdapat perbedaan hasil pembacaan sama seperti pada pembacaan $C O$ pada tabel pengujian $C O$. Pembacaan pada alat uji emisi (prototype) pada putaran 1300 RPM menunjukkan hasil pembacaan $H C$ sebesar 292 ppm, pada putaran 1500 RPM menunjukkan hasil pembacaan $H C$ sebesar 182 ppm, pada putaran 2000 RPM menunjukkan hasil pembacaan $H C$ sebesar 95 ppm, pada putaran 2500 RPM menunjukkan hasil pembacaan $H C$ sebesar 128 ppm, pada putaran 3000 RPM menunjukkan hasil pembacaan $H C$ sebesar 129 ppm.

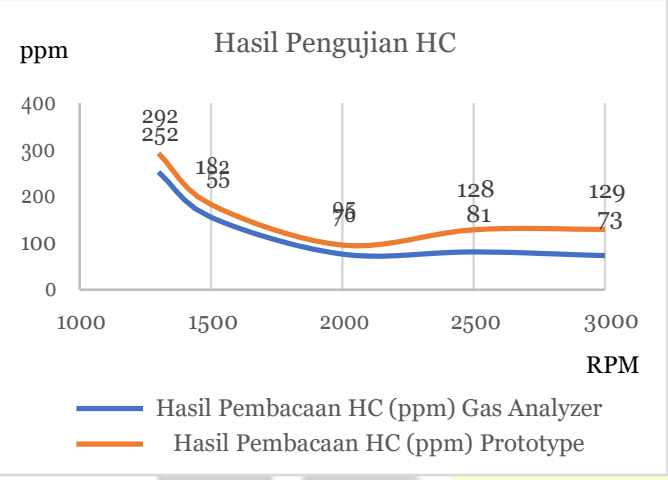

Gambar 10. Grafik Hasil Pengujian HC (ppm)

Adapun kriteria pengujian yang digunakan adalah jika nilai probabilitas ( $\mathrm{sig}$ ) lebih besar dari $a=$ 0.05 maka ada hasil yang signifikan dengan alat uji resmi, sebaliknya jika nilai probabilitas (sig) lebih kecil dari $a=0.05$ maka alat uji (prototype) dapat digunakan seperti alat uji resmi (gas analyzer). Dari data hasil uji $\mathrm{T}$ yang dilakukan dapat diketahui nilai signifikasi pembacaan kadar CO sebesar 0.319 dan kadar $H C$ sebesar 0.896 , nilai tersebut lebih besar dari nilai $a$, maka dapat disimpulkan bahwa pembacaan kadar $C O$ dan $H C$ pada alat uji emisi (prototype) memiliki perbedaan yang signifikan dengan alat uji resmi (gas analyzer).

\section{PENUTUP}

\section{Simpulan}

Dari penelitian yang telah dilakukan maka didapatkan desain alat uji yang sesuai dengan desain yang dirancang oleh peneliti dengan dimensi $12.5 \mathrm{~cm}$ x $11.5 \mathrm{~cm}$ x $7 \mathrm{~cm}$. Alat ini berfungsi mendeteksi kadar $C O$ dan $H C$ pada emisi gas buang motor Jupiter MX King dengan 


\section{Rancang Bangun Alat Uji Emisi Ekonomis Berbasis Arduino}

menggunakan dua sensor gas yaitu sensor $M Q 2$ dan sensor $M Q 9$. Emisi gas buang yang masuk ke dalam pipa PVC pada alat uji emisi (prototype) akan terdeteksi oleh kedua sensor yang terhubung dengan arduino, selanjutnya akan ditampilkan pada layar LCD dalam bentuk angka digital. Pada alat ini program yang digunakan adalah pemrograman Bahasa $\mathrm{C}$.

Cara pengujian emisi gas buang menggunakan alat uji emisi yang dibuat dapat dilakukan dengan mudah dan dapat dilakukan oleh siapapun, karena memiliki desain yang simpel dan mudah digunakan. Pengujian dilakukan dengan keadaan motor pada transmisi Netral (N), selanjutnya selang yang terhubung dengan pipa PVC yang terdapat pada alat uji emisi (prototype) dimaskkan ke dalam lubang saluran gas buang (knalpot) agar emisi dapat terbaca oleh kedua sensor sehingga kadar $C O$ dan $H C$ dapat ditampilkan pada layar LCD.

Hasil pengujian kadar $C O$ dan $H C$ pada alat uji emisi (prototype) dengan hasil pengujian mengunakan alat uji emisi resmi (gas analyzer) masih menunjukkan perbedaan yang signifikan dengan nilai signifikasi pembacaan kadar $\mathrm{CO}$ sebesar 0.319 dan kadar $H C$ sebesar 0.896. Nilai tersebut lebih besar dari nilai $a=$ 0.05 .

\section{Saran}

Pembuatan alat uji sebaiknya menggunakan material yang tahan terhadap uap panas yang dihasilkan oleh emisi gas buang sehingga alat uji dapat bertahan lebih lama dan juga perbaikan dalam desain software terutama dalam pembacaan sensor sehingga hasil pembacaan kadar $\mathrm{CO}$ dan $\mathrm{HC}$ antara alat uji (prototype) dengan gas analyzer tidak terjadi perbedaan yang signifikan.

Pengujian emisi sebaiknya dilakukan dengan rentang waktu tidak terlalu lama untuk menjaga agar tidak ada uap gas yang mengendap pada kepala sensor.

\section{DAFTAR PUSTAKA}

Arifin, Zainal dan Sukoco. 2009. Pengendalian Polusi Kendaraan. Bandung: Alfabeta.

Basrie, Reynold. 2013. Pengertian Emisi dan Efeknya Bagi Kehidupan. Padang: https://reyismyname.blogspot.co.id (diakses tanggal 22 februari2018).

Hermawan, Trian. 2017. Mengenal Sensor MQ2

Sebagai Sensor Pendeteksi Asap: http://trianhermawan.blogspot.co.id (diakses tanggal 22 februari 2018).

Hidayat, Anwar. 2017. Uji F dan Uji T: https://www.statistikian.com/2013/01 /uji-f-dan-uji-t.html/amp (diakses tanggal 20 maret 2018).

Hidayat, Wahyu. 2015. Rancang Bangun Alat Uji Emisi Portabel Gas CO, Nox, Dan HC Pada Kendaraan Bermotor. Semarang: Universitas Negeri Semarang.

Irwanto, Ikhsan. 2017. Implementasi Arduino Dalam Rancang Bangun Alat Uji Emisi Kendaraan Bermotor Berbasis Android. Padang: STMIK Jayanusa Padang.

Palocz-Andresen, Michael. 2013. Decreasing Fuel Consumption And Exhaust Gas Emissions In Transportation. Germany: Springer.

Peraturan Menteri Lingkungan Hidup No. 05 Tahun 2006 tentang Ambang Batas Emisi Kendaraan Bermotor. Jakarta.

Pressman, Roger S and David L. 2009. Web Engineering 1st. New York: McGraw-Hill. Pressman, Roger S. 2010. Software Engineering 7th. New York: McGraw-Hill.

Siregar, Indra Herlamba. 2007. Mesin Konversi Energi. Surabaya: Unesa University Press.

Sugiyono. 2000. Metodologi Penelitian. Bandung: Alfabeta.

Tugaswati, Tri. 2004. Emisi Gas Buang Kendaraan Bermotor Dan Dampaknya Terhadap Kesehatan. Jakarta.

Warju. 2013. Teknologi Reduksi Emisi Gas Buang Kendaraan Bermotor. Surabaya: Unesa University Press.

Yamaha, Indonesia Motor. 2016: www.yamahamotor.co.id/product/mx-king-150 (diakses tanggal 20 juli 2018). 